surgery provided tissue stabilization adjacent to the infundibulum, prevented pseudoaneurysm expansion, and minimized risk of rupture. We hypothesize that low right ventricular pressures and containment of the pseudoaneurysm by scar tissue from prior cardiac surgery allowed time for healing and obviated the need for surgery.

\section{CONCLUSIONS}

In selected patients with imaging studies strongly suggestive of traumatic RV pseudoaneurysms and a history of sternotomy, nonoperative management with close monitoring may be considered in the absence of tamponade, increase in pericardial effusion, severe pulmonary hypertension, deterioration in hemodynamic status, or expansion of the suspicious findings on serial imaging studies.

\section{References}

1. Yeo TC, Malouf JF, Oh JK, Seward JB. Clinical profile and outcome in 52 patients with cardiac pseudo-aneurysm. Ann Intern Med. 1998;128:299-305.

2. Milgalter E, Uretzky G, Levy P, Appelbaum A, Borman JB. Pseudo-aneurysm of the left ventricle. Thorac Cardiovasc Surg. 1987;35:20-25.

3. Vlodaver Z, Coe JI, Edwards JE. True and false left ventricular aneurysms. Propensity for the latter to rupture. Circulation. 1975;51:567-72.

\title{
Successful Fontan completion in a patient with noncompaction myocardium
}

\author{
Yoshinori Miyahara, $\mathrm{MD}, \mathrm{PhD}$, Shingo Kasahara, $\mathrm{MD}, \mathrm{PhD}$, Kozo Ishino, $\mathrm{MD}, \mathrm{PhD}$, \\ Shigeru Sakurai, MD, and Shunji Sano, MD, PhD, Okayama, Japan
}

Noncompaction myocardium is a rare cardiomyopathy that represents numerous prominent trabeculations and deep intertrabecular recesses mainly in the left ventricle $(\mathrm{LV}) .{ }^{1}$ The cause of noncompaction myocardium is thought to be abnormal cessation of endomyocardial morphogenesis. Although noncompaction myocardium has been commonly described in association with other structural heart abnormalities, ${ }^{2}$ few operative outcomes have been reported. We describe a successful surgical case of tricuspid atresia with noncompaction myocardium.

\section{CLINICAL SUMMARY}

A 22-year-old man was referred to the Okayama University Graduate School of Medicine, Dentistry, and Pharmaceutical Sciences for dyspnea on exertion and progressive cyanosis (oxygen saturation $\left[\mathrm{SPO}_{2}\right] 75 \%$ on room air, New York Heart Association II). Tricuspid atresia with normally related great vessels, pulmonary stenosis, and noncompaction myocar-

\footnotetext{
From the Department of Cardiovascular Surgery, Okayama University Graduate School of Medicine, Dentistry, and Pharmaceutical Sciences, Okayama, Japan. Disclosures: None.

Received for publication Sept 27, 2008; accepted for publication Feb 24, 2009; available ahead of print June 12, 2009.

Address for reprints: Yoshinori Miyahara, MD, PhD, Department of Cardiovascular Surgery, Okayama University Graduate School of Medicine, Dentistry, and Pharmaceutical Sciences, 2-5-1 Shikata-cho, Okayama, 700-8558, Japan (E-mail: giten@fd5.so-net.ne.jp).

J Thorac Cardiovasc Surg 2010;139:e85-7

0022-5223/\$36.00

Copyright (c) 2010 by The American Association for Thoracic Surgery doi:10.1016/j.jtcvs.2009.02.056
}

dium had been diagnosed in the patient at birth. On admission, the patient was active $(156 \mathrm{~cm}, 33 \mathrm{~kg})$ with a normal cardiothoracic ratio and sinus rhythm with incomplete left bundle branch block. Echocardiogram showed spongiform myocardium only in the LV myocardium, large atrial and ventricular communications, and an ejection fraction of $40 \%$. Angiogram demonstrated a single left coronary artery, markedly protuberant trabeculations, and deep intertrabecular recesses in the whole LV (Figure 1, $A, B$ ), as observed by computed tomography (Figure 1,C). Hemodynamic data showed a mean superior vena cava (SVC) and inferior vena cava (IVC) pressure of $8 \mathrm{~mm} \mathrm{Hg}$, a mean pulmonary artery (PA) pressure of $11 \mathrm{~mm} \mathrm{Hg}$, PA resistance index of 1.7 Wood unit $/ \mathrm{m}^{2}, \mathrm{LV}$ end-diastolic pressure of $7 \mathrm{~mm} \mathrm{Hg}$, and a pulmonary to systemic flow ratio of 0.96 . In view of the social activity of this young patient and preserved cardiac function, we decided to conduct a staged-Fontan surgery.

The patient was then scheduled to undergo an elective bidirectional Glenn shunt. Anastomosis between the SVC and the right PA was performed without cardiac arrest, using temporary bypass from the SVC through the right atrium, leaving pulmonary antegrade flow. Weaning from circulatory bypass was uneventful, as was the postoperative course, maintaining an $\mathrm{SPO}_{2}$ in the mid 80s until total cavopulmonary connection.

Two years after the bidirectional Glenn shunt, however, this patient had intracerebral hemorrhage caused by arteriovenous malformation and received an emergency coil embolization. He recovered without physical and mental disability. During admission, incidental Holter electrocardiogram 

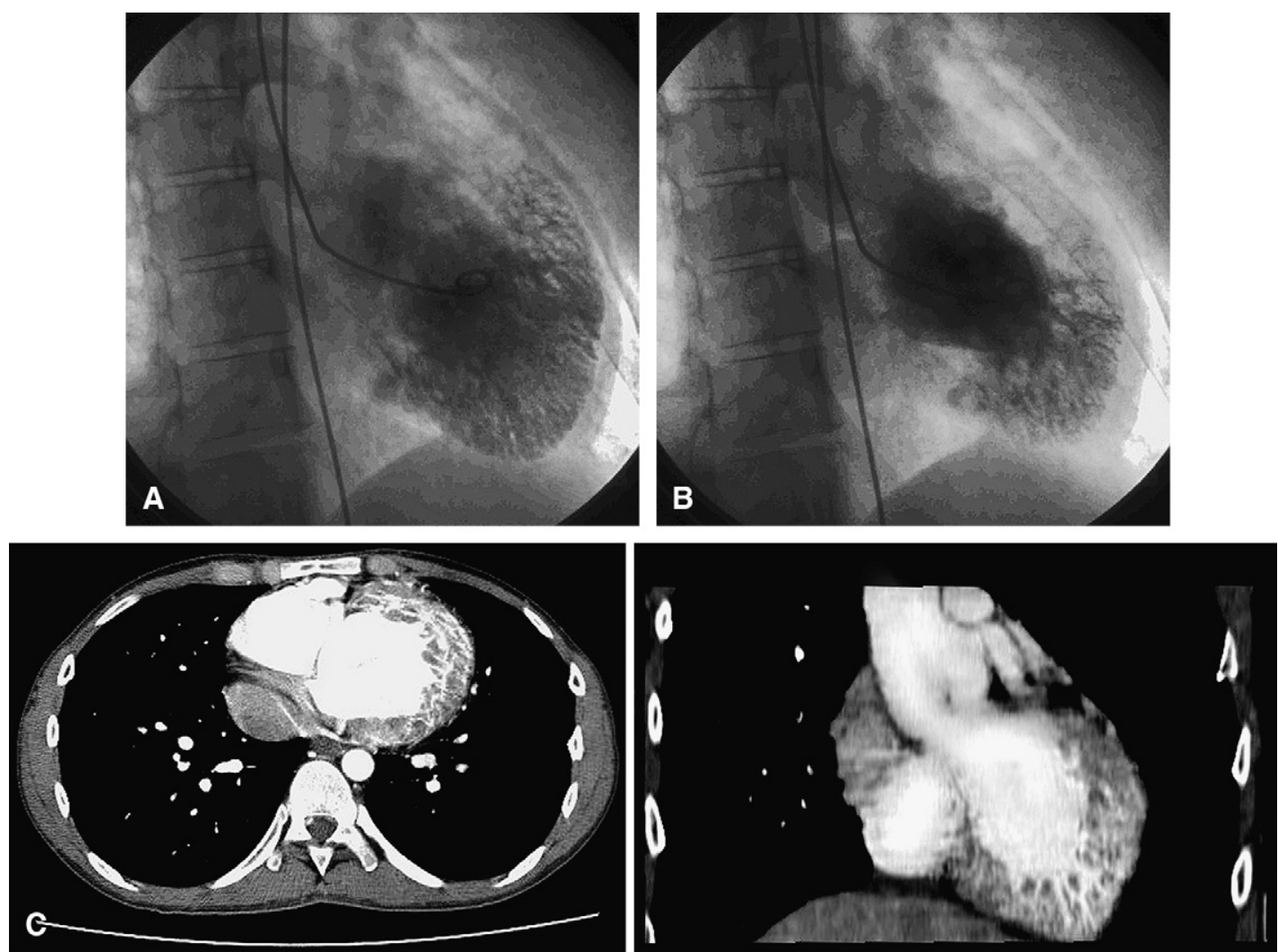

FIGURE 1. Prominent thick trabeculations and deep intertrabecular recesses in the whole left ventricular wall are shown by LV angiogram at diastolic (A) and systolic $(\mathrm{B})$ phases (cardiothoracic ratio $=53 \%$ ). C, Spongiform myocardium depicted by computed tomography.
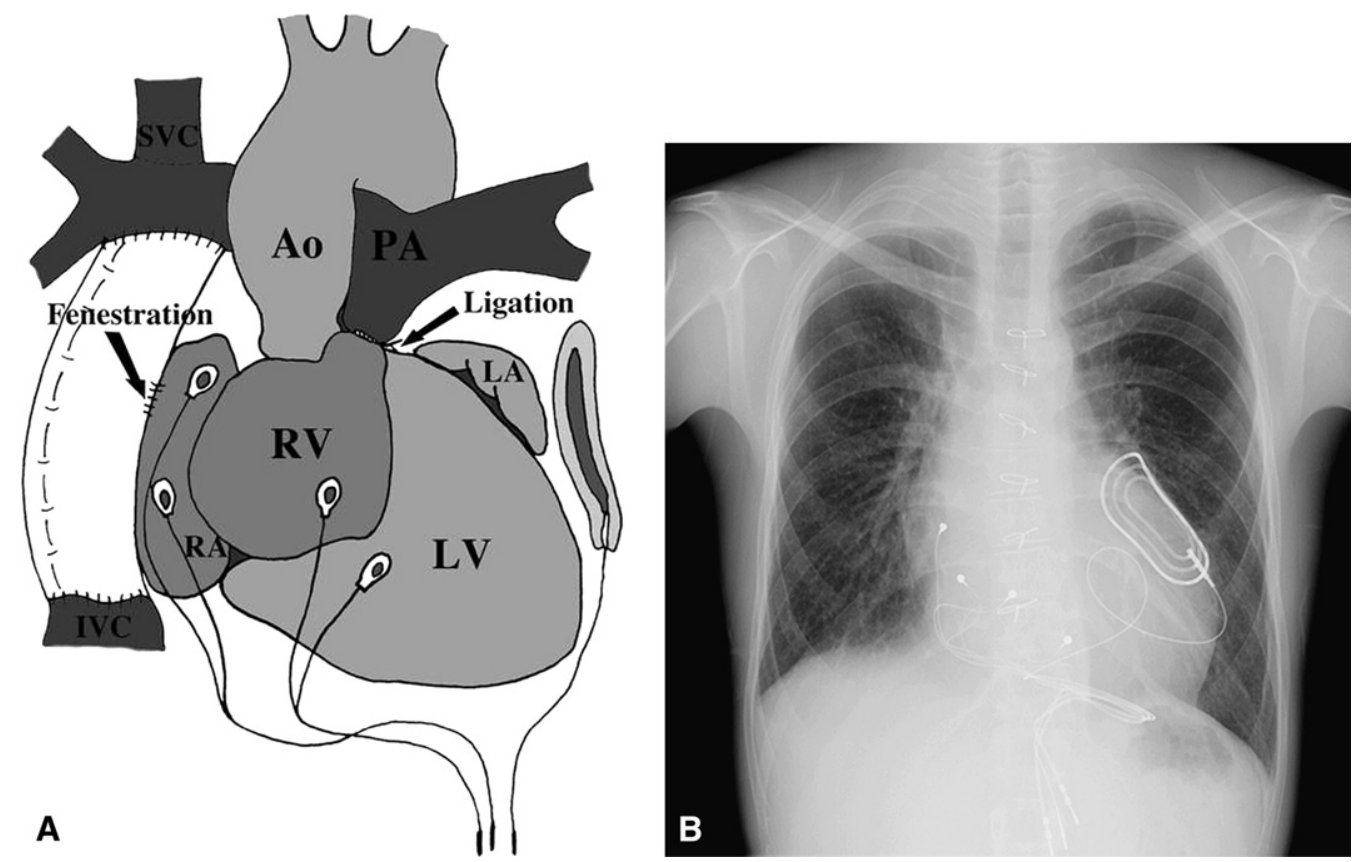

FIGURE 2. A, Schema of Fontan operation. B, Postoperative chest $\mathrm{x}$-ray 7 months after Fontan procedure. CTR $=53 \%$. Ao, Aorta; $P A$, pulmonary artery; $L V$, left ventricle; $R V$, right ventricle; $L A$, left atrium; $R A$, right atrium; $S V C$, superior vena cava; $I V C$, inferior vena cava. 
detected symptomatic nonsustained ventricular tachycardia. Hemodynamic data of the pre-Fontan catheter showed a mean SVC and PA pressure of $9 \mathrm{~mm} \mathrm{Hg}$, a mean IVC pressure of $6 \mathrm{~mm} \mathrm{Hg}$, a PA resistance index of $1.1 \mathrm{Wood}$ unit $/ \mathrm{m}^{2}$, and an LV end-diastolic pressure of $5 \mathrm{~mm} \mathrm{Hg}$.

Four years after the bidirectional Glenn shunt and another therapy for atypical mycobacteriosis, total cavopulmonary connection was performed. Cardiopulmonary bypass was established by ascending aorta and bicaval drainage. Extracardiac conduit was interposed between the IVC and the right PA with 4-mm fenestration (Figure 2, A). These procedures were also performed without cardiac arrest. Cardiopulmonary bypass was uneventfully weaned with low-dose catecholamine support. Finally, implantable cardioverter defibrillator leads were applied. The patient was extubated in the operating room, and anticoagulant plus antiplatelet therapy was commenced postoperatively. Although fluid leakage from bilateral thoracic cavities continued for 4 weeks, there was no episode of ventricular tachycardia during hospital stay. This patient was discharged on postoperative day 44 with an $\mathrm{SPO}_{2}$ of $94 \%$ on room air. Hemodynamic data obtained 1 year after the operation showed a mean SVC, IVC, and PA pressure of $8 \mathrm{~mm} \mathrm{Hg}$, a PA resistance index of $1.2 \mathrm{Wood}$ unit $/ \mathrm{m}^{2}$, and an LV end-diastolic pressure of $5 \mathrm{~mm}$ $\mathrm{Hg}$. Ejection fraction and $\mathrm{SPO}_{2}$ on a patent fenestration flow were $44 \%$ and $92 \%$, respectively. During outpatient followup, chest radiography showed no signs of heart failure (New York Heart Association I) (Figure 2, B).

\section{DISCUSSION}

Noncompaction myocardium is an unclassified cardiomyopathy that is usually associated with other congenital cardiac defects. ${ }^{1,2}$ It is well known that the poor clinical prognosis of patients with the isolated form is the result of progressive ventricular dysfunction, a variety of arrhythmia, and systemic thromboembolism. ${ }^{1,3}$
In the present case, our strategy and management to treat this patient were as follows. First, a staged-Fontan surgery achieved ventricular unloading and increased oxygen saturation, avoiding sudden hemodynamic change, for which LV contractility may be conserved. Second, we preserved pulsatile blood flow during cardiopulmonary assist. Although the mechanism of the progressive ventricular dysfunction in noncompaction myocardium has yet to be elucidated, recent reports implicate that coronary malperfusion in the numerous prominent trabeculae is attributable to development of myocardial fibrosis on the basis of pathologic analysis. ${ }^{4,5}$ Therefore, avoidance of cardiac arrest may maintain coronary microcirculation. To prevent ventricular tachycardia and systemic thromboembolism, we implanted a cardioverter defibrillator and administered both anticoagulant and antiplatelet agents.

\section{CONCLUSIONS}

Noncompaction myocardium presents a surgical challenge because of its poor clinical prognosis and associated cardiac defects. However, a single ventricle with noncompaction myocardium is not a contraindication for Fontan completion. To our knowledge, this is the first report of a successful Fontan completion for noncompaction myocardium.

\section{References}

1. Chin TK, Perloff JK, Williams RG, Jue K, Mohrmann R. Isolated noncompaction of left ventricular myocardium. A study of eight cases. Circulation. 1990;82:507-13.

2. Ozkutlu S, Ayabakan C, Celiker A, Elshershari H. Noncompaction of ventricular myocardium: a study of twelve patients. J Am Soc Echocardiogr. 2002;15:1523-28.

3. Murphy RT, Thaman R, Blanes JG, Ward D, Sevdalis E, Papra E. Natural history and familial characteristics of isolated left ventricular non-compaction. Eur Heart J. 2005;26:187-92.

4. Jenni R, Wyss CA, Oechslin EN, Kaufmann PA. Isolated ventricular noncompaction is associated with coronary microcirculatory dysfunction. J Am Coll Cardiol. 2002;39:450-4.

5. Oechslin EN, Attenhofer Jost CH, Rojas JR, Kaufmann PA, Jenni R. Long-term follow-up of 34 adults with isolated left ventricular noncompaction: a distinct cardiomyopathy with poor prognosis. J Am Coll Cardiol. 2000;36:493-500. 